\title{
Computational docking study of multitarget bioactive compounds in Indonesia traditional herbal medicine for tuberculosis therapy
}

\author{
Sherry Aristyani, Sri Widyarti, Sutiman B. Sumitro
}

Department of Biology, Faculty of Mathematics and Natural Sciences, University of Brawijaya, Malang, Indonesia

\begin{abstract}
Introduction: Tuberculosis (TB) is one of the leading infectious diseases in the world. It is commonly infected by Mycobacterium tuberculosis (TB) and can rapidly spread through droplet transmission. Poverty and malnutrition cause immunodeficiency, and thus, it increases the risk factor for TB. Indonesia traditional herbal medicine, jamu, has been using for long time to treat diseases involving TB. This research makes new jamu formulation from Curcuma xanthorrhiza Roxb., Tamarindus indica L., Citrus aurantifolia, and Zingiber officinale var. rubrum and analyzes the formulation with docking method. Materials and Methods: Protein targets used were from human matrix metallopeptidase 1 and Src and form MTB PknB and catalase-peroxidase. Compound-target proteins and protein-protein docking were conducted by PatchDock and FireDock. Results and Discussion: The docking results were analyzed and visualized using LigPlot ${ }^{+}$and PyMoL. Lipinski's rule and toxicity were checked by SwissADME and AdmetSAR. The result showed that 6 compounds from 223 compounds (not 222 compounds, but 223 compounds) analysed could play as multitarget compounds inhibiting four target proteins. In addition, two compounds were found which could change the binding location of Src and PknB coproteins. Conclusion: According to the results, the new jamu formulation has the potential to utilize as TB therapy.
\end{abstract}

Keywords: Jamu, molecular docking, multitarget compounds, tuberculosis

\section{INTRODUCTION}

$\mathrm{T}$ Tuberculosis (TB) is one of the infectious respiratory diseases caused by airborne bacteria, Mycobacterium TB. TB causes main primary high mortality and morbidity in the world, and numerous new TB cases are arised annually. In 2014, it has been recorded that 9.6 million incident cases were discovered. ${ }^{[1]}$ However, more than $95 \%$ of death patients of TB occurs in low- and middleincome countries, and it means that there is high correlation between poverty and TB infection. ${ }^{[2]}$ Poverty causes deployment of TB, the majority through (1) living condition like living in the overcrowded place, slum, and poorly ventilated home, (2) prolong delaying checkup, and (3) malnutrition and/or HIV infection. ${ }^{[3]}$ These facts match with TB dissemination case in Indonesia, which the regions with high TB transmission have high populated area, malnutrition cases, and HIV infection. ${ }^{[4]}$ In addition, according to the WHO annotation, the reason of failure TB treatment is caused by the degree of poverty, difficulty to reach medical facilities, lack of medical staff, the high cost of TB drugs, and complicate procedure. ${ }^{[5]}$ Malnutrition has a close link with infection; it causes immunodeficiency and enhances TB risk factor. Based on animal studies, insufficient nutrition intake reduces helper $\mathrm{T}$ cell 1 (Th1) cytokine secretion such as interferon- $\gamma$, interleukin-2, and tumor necrosis factor- $\alpha$ which had a role as mycobacteria infection control, reduce NO production, and also gain transforming growth factor beta production suppressing inflammation cytokine to eradicate mycobacteria. ${ }^{[6]}$

\section{Address for correspondence:}

Sutiman B. Sumitro, Department of Biology, Faculty of Mathematics and Natural Sciences, University of Brawijaya, Malang, Indonesia. Phone: +62341-554403. E-mail: sutiman@ub.ac.id

Received: $23-05-2018$

Revised: 03-09-2018

Accepted: 10-10-2018 
The use of common TB medication causes TB cases which have been developing lately. For a long time, common medicine for treating TB has been isoniazid, rifampicin, pyrazinamide, and ethambutol(first-linedrug). Unfortunately, these drugs cause rapid evolution and result resistant to MTB. Furthermore, this case leads to multidrug-resistant TB (MDR-TB) and makes TB more serious and difficult to treat. ${ }^{[7]}$ Second-line drugs such as aminoglycosides, polypeptides, fluoroquinolones, thioamides, cycloserine, and para-aminosalicylic have been used to treat MDR-TB; however, so far, these drugs cause mutation and emerge extensively drug-resistant TB (XDR-TB) case. XDR-TB is described as MTB not only resistant to first-line drugs but also to second-line drugs. ${ }^{[8]}$ From these reasons, it can be concluded TB therapy focusing only to exterminate bacteria cause mutation and make diseases more severe and hard to cure. Nowadays, for overcoming TB cases, multiple therapies which can eradicate mycobacteria, improve nutrition, and balance immunity and the human system should be developed.

Jamu is Indonesia traditional herbal medicine that has been used for a long time ago in Indonesia community for maintaining health and treating diseases. Jamu is a traditional medication from ancestor and still popular in rural and urban areas. ${ }^{[9]}$ In jamu production, people use various plants which are easy to found in their environment. For resolving TB case, this study tries to make new jamu formulation form Indonesia medical plants that used Indonesia local people to treat TB, Curcuma xanthorrhiza Roxb., Tamarindus indica L., Citrus aurantifolia, and Zingiber officinale var. rubrum. Some reports have shown that all of these plants had the ability as antimicrobial and immunostimulation. ${ }^{[10-12]}$ For analyzing the effect toward $\mathrm{TB}$, in silico docking method was used in this study. The targets protein selected were not only from MTB for eradicating mycobacteria but also from a human for regulating defense mechanism, matrix metallopeptidase 1 (MMP1), tyrosine-protein kinase Src, protein kinase (PknB), and catalase-peroxidase (KatG).

MMPs are a member of zinc-dependent protease that has two conserved domains as a predominant and a catalytic domain. MMPs can degrade components of extracellular matrix-like collagens, laminin, fibronectin, vitronectin, and proteoglycans. MMP activity is controlled by the gene expression and proenzyme activation. Tissue inhibitor of metalloproteinase is an inhibitor of MMPs. High activity of MMP can induce diverse pulmonary disease caused by extracellular matrix destruction. ${ }^{[13]}$ In TB patients, MMP1 has been found had upregulation, and MTB caused high expression of MMP1. The excessive of MMP1 leads to granuloma degradation, thus causing mycobacteria disseminate to another part of the human body. ${ }^{[14,15]}$

Src protein-tyrosine kinase, a non-receptor proteintyrosine kinase, is a proto-oncogene that is important for cell morphology, motility, proliferation, and survival. Src structure contains the $\mathrm{SH} 3$ domain, a protein-tyrosine kinase domain, and SH2 domain, C-terminal regulatory tail.[16] $\mathrm{PknB}$ is a transmembrane signaling kinase which has a signal recognition domain and an intracellular kinase domain. PknB plays as cell growth and division regulator in MTB. PknB encoded by $P k n B$ which is part of the operon carrying cistron coding involved cell shape control. ${ }^{[18,19]}$

KatG is a multifunctional catalase-peroxynitrite and NADH oxidase. By the KatG enzyme, INH is changed into INHNAD which can interfere with activation inhibiting NADHdependent enoyl-ACP reductase (inhA) in mycolic acid biosynthesis process. Mutation in $k a t G$ and inhA is associated with isoniazid resistance. Reduction of catalase or peroxidase activity is the result of kat $G$ mutation in which most common mutation is in S315T. In addition, mutation in inhA causes resistance to isoniazid and ethionamide. inhA mutation occurs commonly in its promoter region and it associates with monoresistant strains. ${ }^{[20]}$

\section{MATERIALS AND METHODS}

\section{Ligand Preparation}

There were 55 compounds of C. xanthorrhiza Roxb., 59 compounds of $Z$. officinale var. rubrum, 55 compounds of T. indica L., and 54 compounds of C. aurantifolia. All threedimensional (3D) structure of the compounds and other 3D chemicals such as mitoxantrone, cyanidin, dasatinib, morin, and isoniazid were obtained from PubChem (https:// pubchem.ncbi.nlm.nih.gov/).

\section{Protein Preparation}

Target proteins used were PknB and KatG from MTB and MMP-1 and Src from human. Protein 3D structures were obtained from Protein Data Bank (http://www.rcsb.org/); the PDB code is as follows: PknB (2FUM), ForkHead Associated A (FhaA) (3PO8), KatG (1SJ2), MMP1 (3SHI), Src (1FMK), and PIK3 (3L54). The controls used were determined by the following: Mitoxantrone-PknB bond, isoniazid-KatG bond, doxycycline-MMP1 bond, and saracatinib-Src bond. The water molecules in proteins were omitted using Discovery Studio 2016 before docking process.

\section{Docking Simulation and Interaction Analysis}

Patchdock was used for docking protein-bioactive compounds and complex protein-protein. ${ }^{[21,22]}$ It presents geometry-based molecular docking algorithm and gives geometry shape complementarity score, area, atomic contact energy (ACE), and 3D transformation outputs; nevertheless, the highest geometry shape complementarity score was chosen. Root mean square deviation (RMSD) value 1.5 was 
used for docking protein compounds, and RMSD value 4.0 was used for docking complex protein-protein. For proteinprotein docking, Firedock was used to refine protein-protein docking. It shows binding energy or global energy value, attractive and repulsive Van der Waals force value, ACE, and the contribution hydrogen bounds to global binding energy (HB), but only the highest binding energy was used in this study. ${ }^{[23,24]}$ LigPlot $^{+}$was used to analyze the ligandprotein structure and binding after docking process. ${ }^{[25]}$ This program showed 2D structure of position and interaction ligand in protein. The results showed H-bond interactions and distance, hydrophobic interaction, and external binding. The result of protein-protein dockings were visualized with PyMoL.

\section{Chemical Information and Toxicity}

Swiss ADME was used to calculate Lipinski's rule of five. The toxicity was analyzed with AdmetSAR. ${ }^{[26,27]}$

\section{RESULTS}

\section{Active Compound Docking}

According to the docking screening of 223 compounds' result, it has been chosen highest ten top best scores of each proteinligand docking by PatchDock [Table 1]. 17 compounds were selected based on ten highest score from docking result. Each of the compounds had various pattern scores while docked with target proteins. Phenol compounds such as curcumin and demethoxycurcumin had supreme binding energy score while docked with MTB PknB and KatG and human MMP1, whereas an organic compound, oleic acid, had the first score when docked with Src of human.Moreover, the docking results presented that curcumin, demethoxycurcumin, phytol, oleic acid, and linoleic acid [Figure 1] could bind with four target proteins; it might be concluded that these compounds were multitarget compounds. For more exploring, binding interaction and position were analyzed with LigPlus.

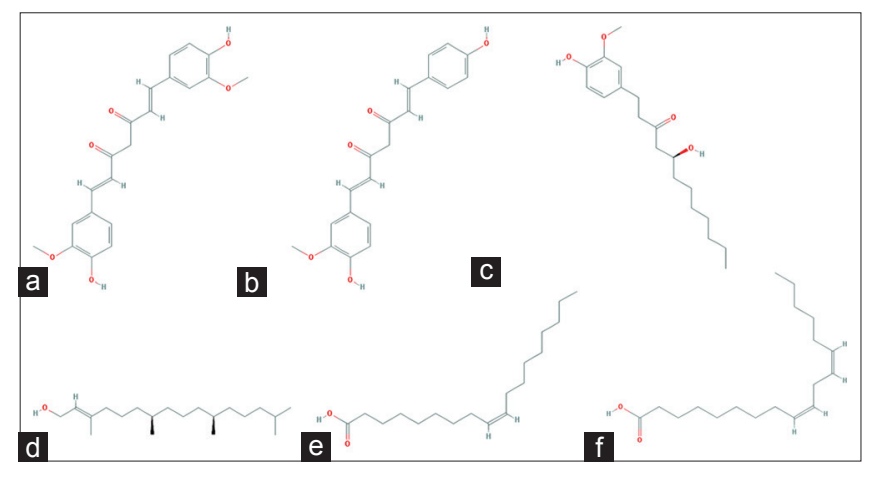

Figure 1: Active compounds of (a) curcumin, (b) demethoxycurcumin, (c) 8-gingerol, (d) phytol, (e) oleic acid, (f) linoleic acid

\section{Active Compounds - human Proteins}

According to Figure 2, the compounds bound with a catalytic domain which is in residues of 106-261 MMP1 ${ }^{[28]}$ Curcumin, demethoxycurcumin, and phytol [Figure 2a,b,d] had one external binding, respectively, with Asn 143, Gln 135, and Thr 148. In addition, curcumin had one hydrogen bound interaction with Tyr201 (2.76 $\dot{A})$, while demethoxycurcumin [Figure 2b] had two hydrogen binding interactions with Phe $149(2.24 \dot{A})$ and Arg $202(2.72 \AA)$. These interaction numbers were less than the control that had three hydrogens bound in Asp124 (2.97 $\dot{A}$ ) and Ser 142 (2.23 $\dot{A}$ and $3.33 \dot{A})$. In contrast, 8- gingerol, oleic acid, and linoleic acid [Figure 2c,e,f] had none of the external binding and hydrogen binding, and it tended to be hydrophobic while contact with MMP1.

When compounds docked with Src, phenol compounds, curcumin, demethoxycurcumin, and 8-gingerol [Figure 3a-c] had the same interaction residues with control [Figure 3f], Thr 247, Phe 150, Leu 161, Ile 153, and Val 399. Moreover, these compounds also interacted with Src in SH3 domain (83-142) and SH3-SH2 interaction domain $(142-146) .{ }^{[29,30]}$ Curcumin and demethoxycurcumin had one hydrogen binding, Lys104 (2.07 ஷं), Val 339 (3.19 $\dot{A})$, and one external binding Lys 104 and Val 339. 8-gingerol and control had one hydrogen binding interaction with $\mathrm{Thr}$ 247 (3.02 A) and Asn397 (2.84 Aे). However, phytol and oleic acid had the same position when interacting with Src, Asn 391, Leu 273, Ser 345, Asp 404, Leu 393, and Asp 348. Oleic acid had a hydrogen binding with Asp 386 (2.97 A), while phytol and linoleic acid tended to be hydrophobic while interacting with Src.

\section{Active Compounds - MTB Proteins}

Based on Figure 4, active compounds had the same position with control, eventhough the binding scores were lower than the control. All the compounds are contact with N-terminal lobes of PknB, Leu 17, Gly 18, Val 25, Ala 38, Met 92, Glu 93, and Val 95 and C-terminal of PknB lobes (exclude curcumin), Met145, and Met155. It has been evident that the connection in this position could suppress the activity of $\mathrm{PknB}$ in MTB ${ }^{\left[{ }^{[1]}\right.}$ Curcumin [Figure 4a] had two hydrogen binding with $\operatorname{Thr} 149(2.81 \dot{A})$ and $\operatorname{Ser} 147(3.23 \dot{A}) ; 8$-gingerol, phytol, and oleic acid [Figure $4 \mathrm{c}$ and $\mathrm{d}$ ] had one hydrogen binding, respectively; Glu 93 (3.15 $\dot{A})$, Asn143 (2.67 $\dot{A})$, and Asp (102), control only had an external binding with Asp126, and linoleic acid had none of the hydrophobic and external binding.

In KatG docking term, the result described that the compounds had different location binding sites [Figure 5]. Curcumin and control [Figure 5a and g] had interaction with Gly 421, Asp 440, Gln 439, and Gly 490, demethoxycurcumin and 8-gingerol interacted with Glu 709, Arg 705, Arg 145, Arg 128, 
Table 1: Ten highest score of screening result

\begin{tabular}{|c|c|c|c|c|c|c|}
\hline \multirow[t]{2}{*}{ Plants } & \multirow[t]{2}{*}{ Compounds } & \multirow[t]{2}{*}{ Class } & \multicolumn{4}{|c|}{ Binding energy score (kcal/mol) } \\
\hline & & & MMP1 & Src & PknB & KatG \\
\hline Curcuma xanthorrhiza Roxb. & Curcumin & Phenol & 5118 & 5140 & 5572 & 5414 \\
\hline Curcuma xanthorrhiza Roxb. & Demethoxycurcumin & & 4802 & 4920 & 5108 & 5692 \\
\hline Curcuma xanthorrhiza Roxb. & Bisdemethoxycurcumin & & - & 5060 & - & - \\
\hline Zingiber officinale var. rubrum & 8-gingerol & & 5222 & 5146 & 5482 & 5430 \\
\hline Zingiber officinale var. rubrum & 8-shogaol & & 4738 & - & 5388 & 5422 \\
\hline Zingiber officinale var. rubrum & 6-gingerol & & - & 4892 & 5002 & - \\
\hline Zingiber officinale var. rubrum & 6-shogaol & & - & - & - & - \\
\hline Zingiber officinale var. rubrum, Citrus aurantifolia & Phytol & Terpenoid & 4730 & 4952 & 5476 & 5370 \\
\hline Curcuma xanthorrhiza Roxb. & Citronellyl pentanoate & & - & - & - & 5320 \\
\hline $\begin{array}{l}\text { Tamarindus indica L., Tamarindus indica L., } \\
\text { Citrus aurantifolia }\end{array}$ & Oleic acid & Organic acid & 4896 & 5190 & 5326 & 5444 \\
\hline Tamarindus indica L., Citrus aurantifolia & Linoleic acid & & 4560 & 5156 & 5216 & 5660 \\
\hline Tamarindus indica $L$. & Heptadecanoic acid & & 4896 & 5038 & - & 5384 \\
\hline Curcuma xanthorrhiza Roxb. & Butyl dodecanoate & & 4610 & - & - & - \\
\hline Tamarindus indica $L$. & Myristic acid & & - & - & - & - \\
\hline Citrus aurantifolia & Palmitic acid & & - & 4976 & - & - \\
\hline Tamarindus indica $L$. & Palmitoleic acid & & 4598 & - & 5230 & 5394 \\
\hline \multirow[t]{2}{*}{ Tamarindus indica L.; Citrus aurantifolia } & Linolenic acid & & - & - & 5318 & - \\
\hline & Control & - & 4856 & 6770 & 5906 & 3088 \\
\hline
\end{tabular}

\begin{tabular}{|c|c|c|c|c|c|}
\hline Compounds & Global energy (kcal/mol) & Attractive VdW & Repulsive VdW & ACE & HB \\
\hline (Src-curcumin)-PI3K & -43.44 & -29.21 & 3.78 & 3.89 & -4.77 \\
\hline (Src-demethoxycurcumin)-PI3K & -45.16 & -35.56 & 13.61 & 5.67 & -6.19 \\
\hline (Src-8-gingerol)- PI3K & -45.16 & -35.56 & 13.61 & 5.67 & -6.19 \\
\hline (Src-phytol)- PI3K & -36.43 & -35.92 & 22.70 & 6.81 & -10.75 \\
\hline (Src-oleic acid)- PI3K & -38.88 & -36.67 & 15.32 & 2.49 & -6.51 \\
\hline (Src-linoleic acid)- PI3K & -43.67 & -38.65 & 23.70 & 5.77 & -7.30 \\
\hline (Src-control)-PI3K & -41.29 & -40.88 & 28.87 & 6.73 & -7.53 \\
\hline Src-PI3K & -43.67 & -38.65 & 23.70 & 5.77 & -7.30 \\
\hline (PknB-curcumin)-FhaA & -46.84 & -29.90 & 14.47 & 2.99 & -8.55 \\
\hline (PknB-demethoxycurcumin)- FhaA & -46.84 & -29.90 & 14.47 & 2.99 & -8.55 \\
\hline (PknB-8-gingerol)- FhaA & -46.84 & -29.90 & 14.47 & 2.99 & -8.55 \\
\hline (PknB-phytol)- FhaA & -47.75 & -44.47 & 24.38 & -3.40 & -10.64 \\
\hline (PknB-oleic acid)- FhaA & -46.84 & -29.90 & 14.47 & 2.99 & -8.55 \\
\hline (PknB-linoleic acid)- FhaA & -46.84 & -29.90 & 14.47 & 2.99 & -8.55 \\
\hline (PknB-control)-FhaA & -46.84 & -29.90 & 14.47 & 2.99 & -8.55 \\
\hline PknB-FhaA & -46.84 & -29.90 & 14.47 & 2.99 & -8.55 \\
\hline
\end{tabular}

PIK3 (PIK3 not P13K): Phosphoinositide 3-kinase, FhaA: ForkHead Associated A

Gly 297, and Glu 289, whereas oleic and linoleic acid had the same position to connect with Asn 44, Lys 46, Glu 195, Asn 35, Gly 32, Gln 36, Gly 33, and Arg 42. Demethoxycurcumin had three hydrogen bindings with Ser 700 (2.81 $\dot{A})$, Asn 41 (3.04 $\dot{\mathrm{A}})$, and Tyr 608 (2.52 $\dot{\mathrm{A}})$; 8-gingerol, oleic acid, and linoleic acid had a hydrogen bindings, respectively, with Glu $709(2.87 \dot{A})$, Gln $36(2.44 \dot{A})$, and Gln $36(3.01 \dot{A})$; curcumin, linoleic acid, and control had an external binding, but phytol had distinct position binding with others and it only had hydrophobic interaction with KatG. 


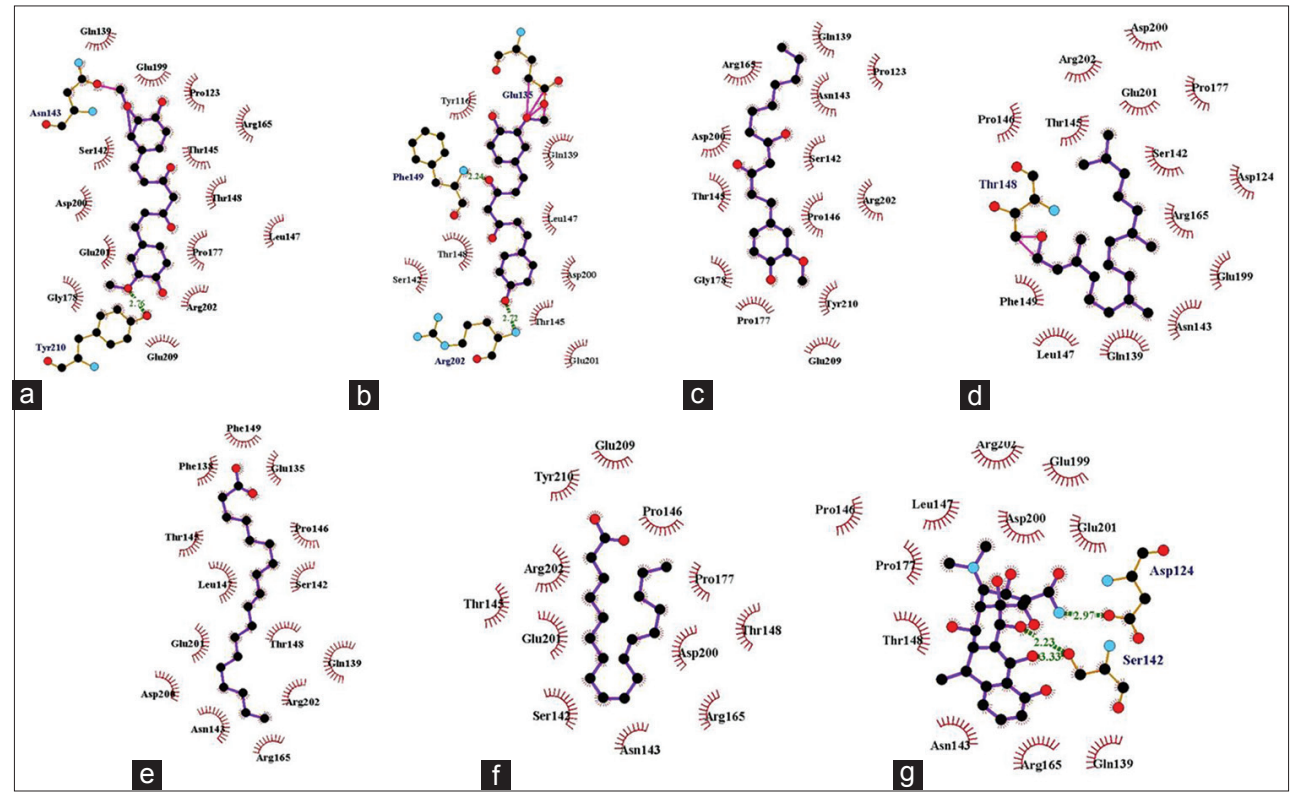

Figure 2: Matrix metallopeptidase 1 - active compounds, (a) curcumin, (b) demethoxycurcumin, (c) 8-gingerol, (d) phytol, (e) oleic acid, (f) linoleic acid, (g) control

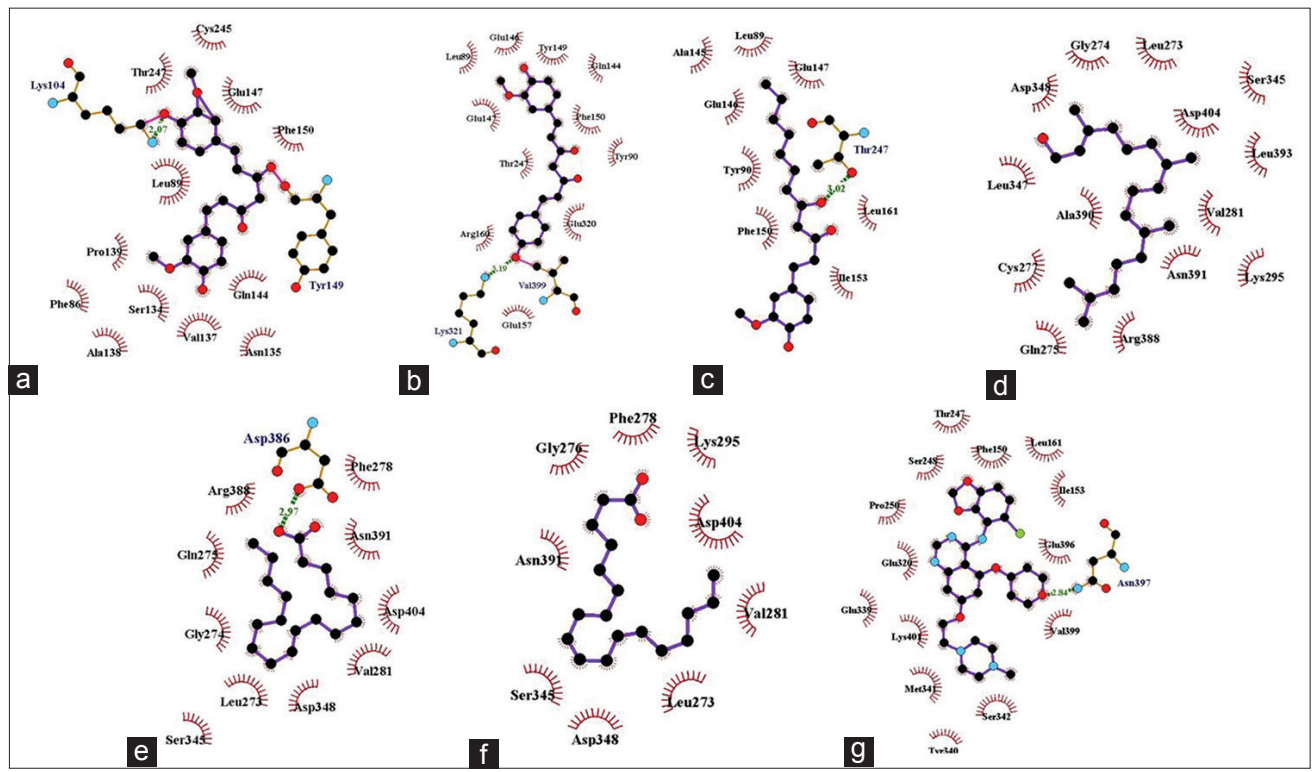

Figure 3: SRC - active compounds, (a) curcumin, (b) demethoxycurcumin, (c) 8-gingerol, (d) phytol, (e) oleic acid, (f) linoleic acid, (g) control

\section{Protein Docking}

In Src and PknB term, binding score with control was higher than with active compounds [Table 1], and for more understanding this case, protein docking between protein target-another with downstream protein was conducted. Src was docked with phosphatidylinositide 3-kinases (PI3K), a protein signal transducer phosphorylating the inositol group of phosphoinositides. Src-PI3K complex can active the AKT/ mTOR pathway involving negative regulator of autophagy, and it has been shown that inhibitor of Src-PIK3 proven to inhibit the survival of MTB. ${ }^{[17,32]}$ However, based on the docking result [Table 2], the global energy value of control was lower
$(-41.29 \mathrm{kcal} / \mathrm{mol})$ than phytol $(-36.43 \mathrm{kcal} / \mathrm{mol})$ and oleic acid $(-38.88 \mathrm{kcal} / \mathrm{mol})$. It was assumed that phytol and oleic acid might be a better inhibitor than saracatinib. PknB was docked with FhaA, the substrate of Ser/Thr protein kinases. It was reported that there was an interaction between $\mathrm{PknB}$ and FhaA for MTB growing process. ${ }^{[33]}$ In addition according to the results, it showed that all of the complexes had same value except complex protein with phytol [Table 2], it had the lowest global energy, indicating that it had robust binding rather than the other complexes. Furthermore, in Src term, according to the visualization of protein docking complex protein with phytol and oleic acid, these compounds could change the conformation of the complex protein [Figure 6]. Not only 


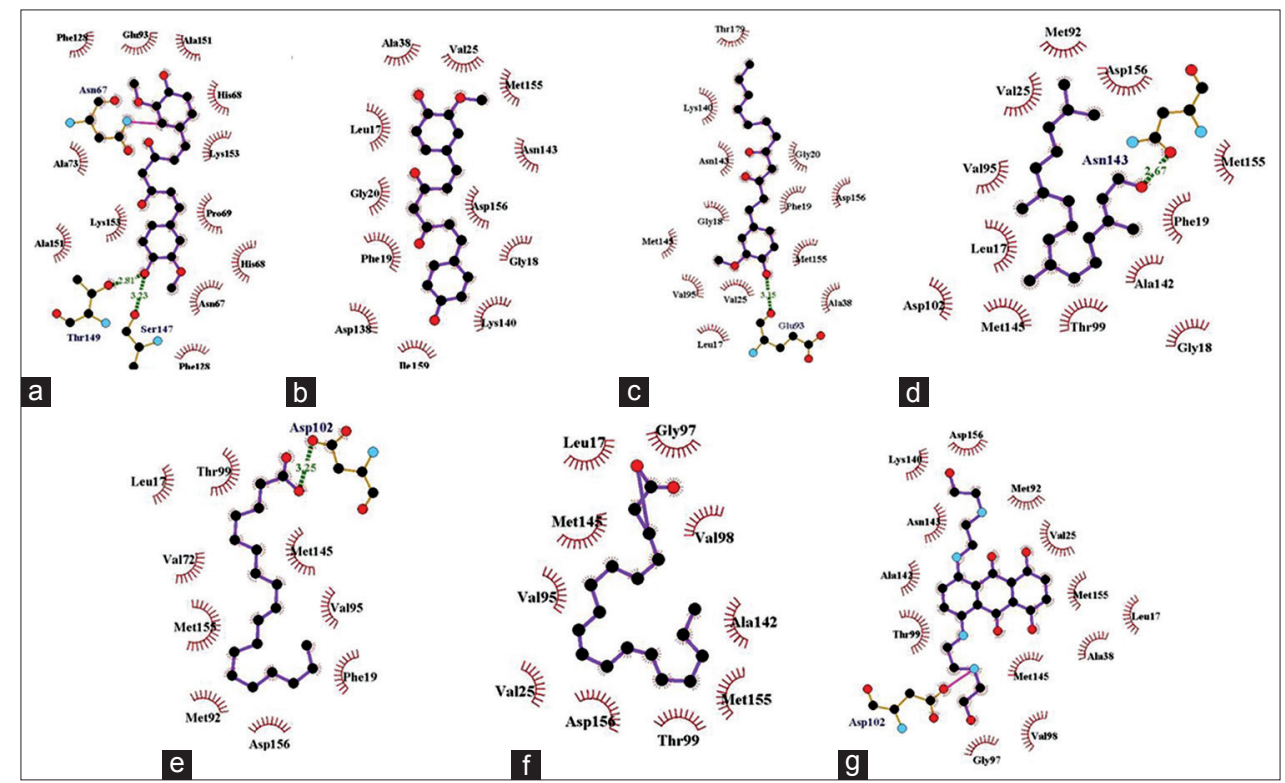

Figure 4: PknB - active compounds, (a) curcumin, (b) demethoxycurcumin, (c) 8-gingerol, (d) phytol, (e) oleic acid, (f) linoleic acid, (g) control

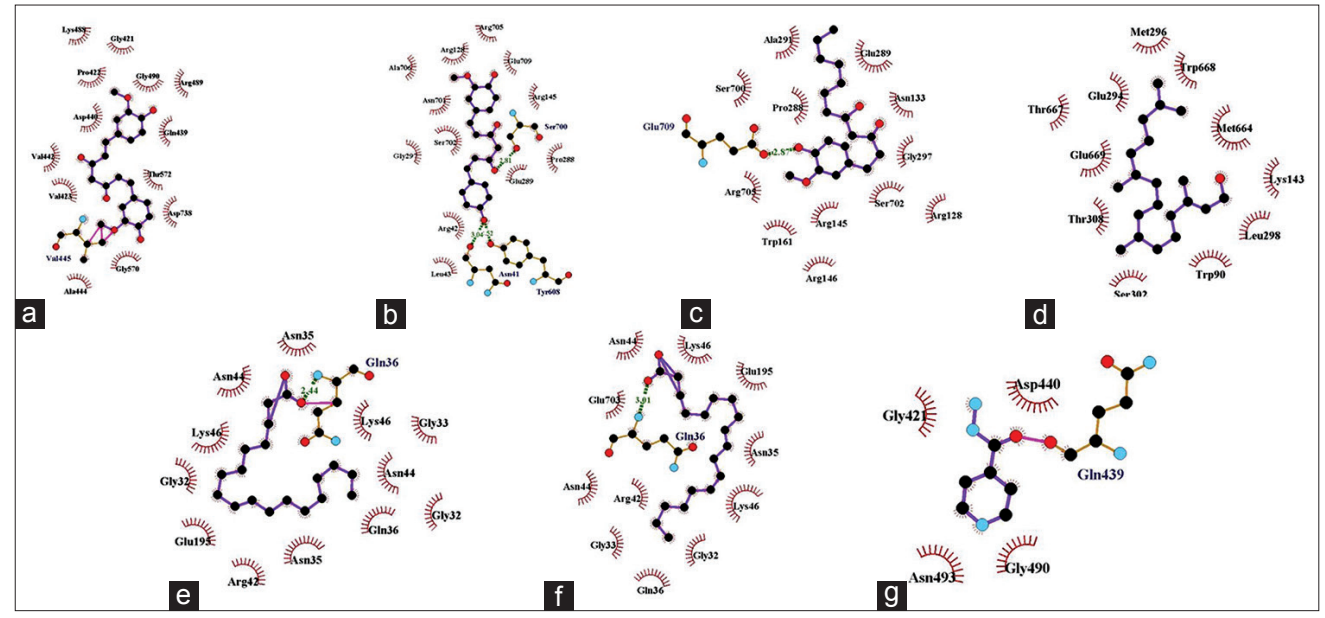

Figure 5: KatG - active compounds (a) curcumin, (b) demethoxycurcumin, (c) 8-gingerol, (d) phytol, (e) control

changing the conformation but also the binding location was different with the control which had the same position with other compounds such as curcumin, demethoxucurcuin, and 8-gingerol. However in PknB case, only phytol could change the conformation of PknB and FhaA. Phytol also had a different position when interacting with $\mathrm{PknB}$, and it seemed that phytol interacts with a distinct chain of PknB.

\section{Lipinski's Rule and Toxicity}

The value of Lipinski's score and toxicity could be seen in Table 3, and it represented that phytol, oleic acid, linoleic acid, mitoxantrone, doxycycline, and saracatinib had a violation even it still allowed in Lipinski's rule. Isoniazid and mitoxantrone had a high probability to cause the mutation in bacteria, and it might induce the bacteria resistance with drugs. All of the compounds showed that it did not induce carcinogen.

\section{DISCUSSION}

C. xanthorrhiza Roxb., Zingiber officinale var. rubrum, T. indica L., Ocimum basilicum, and C. aurantifolia are used by Indonesia local people to treat TB. However, not only in Indonesia but also in other counties use these plants for TB. Furthermore, these plants and the constituents have been evaluated to inhibit the cells growth and infection of MTB. ${ }^{[34-36]}$ According to the result, the plants consisted of six compounds: curcumin, demethoxycurcumin, 8-gingerol, phytol, oleic acid, and linoleic acid which could act as multitarget compounds, inhibiting four targets proteins.

Nowadays, multitarget drug is one possible way that can be developed to overcome TB. Multitarget compounds can target many proteins and it is more effective rather than combination compounds with single target, respectively. There are three types of multitarget inhibitors that can design 
Aristyani, et al.: Docking study of Indonesia herbal medicine

\begin{tabular}{lllllc}
\multicolumn{7}{c}{ Table 3: Ligand property and toxicity } & & \\
Compounds & Lipinski's rule & AMES toxicity & Probability & Carcinogen toxicity & Probability \\
\hline Curcumin & Yes; 0 violation & Non-AMES toxic & 0.9132 & Non-carcinogens & 0.8689 \\
Demethoxycurcumin & Yes; 0 violation & Non-AMES toxic & 0.7747 & Non-carcinogens & 0.8866 \\
8-Gingerol & Yes; 0 violation & Non-AMES toxic & 0.7697 & Non-carcinogens & 0.9121 \\
Phytol & Yes; 1 violation: MLOGP>4.15 & Non-AMES toxic & 0.9132 & Non-carcinogens & 0.5055 \\
Oleic acid & Yes; 1 violation: MLOGP>4.15 & Non-AMES toxic & 0,9674 & Non-carcinogens & 0,6568 \\
Linoleic acid & Yes; 1 violation: MLOGP>4.15 & Non-AMES toxic & 0,9674 & Non-carcinogens & 0,6568 \\
Isoniazid & Yes; 0 violation & AMES toxic & 0,8557 & Non-carcinogens & 0,7514 \\
Mitoxantrone & Yes; 1 violation: $\mathrm{NH}$ or $\mathrm{OH}>5$ & AMES Toxic & 0.9108 & Non-carcinogens & 0.8742 \\
Doxycycline & Yes; 1 violation: $\mathrm{NH}$ or $\mathrm{OH}>5$ & Non-AMES toxic & 0.9132 & Non-carcinogens & 0.8632 \\
Saracatinib & Yes; 1 violation: $\mathrm{MW}>500$ & Non-AMES toxic & 0,5 & Non-carcinogen & 0,9215 \\
\hline
\end{tabular}

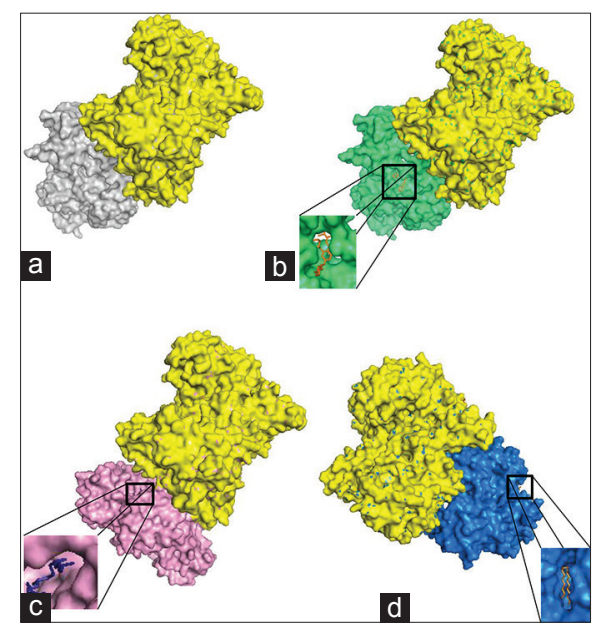

Figure 6: SRC complex (a) SRC-PIK3, (b) (SRC-control)PIK3, (c) (SCR-phytol)-PIK3, (d) (SRC-oleic acid) - PIK3. Gray structure: SRC wild-type protein; yellow structure: PIK3: green structure: SRC-saracatinib complex; pink structure: SRC-phytol; blue structure: SRC-oleic complex

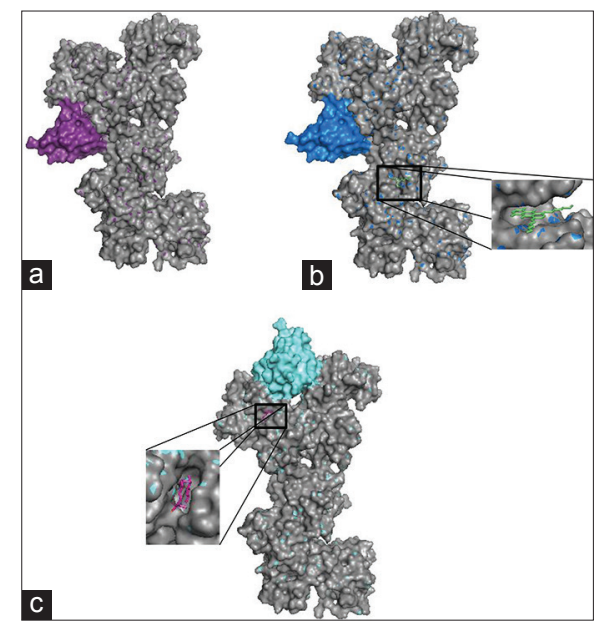

Figure 7: PknB complex, (a) PknB- ForkHead Associated A (FhaA), (b) (PknB - control)-FhaA, (c) (PknB -phytol)-FhaA gray structure: PknB; purple: FhaA in PknB-FhaA complex; dark blue: FhaA in PknB -(PknB -mitoxantrone)-FhaA complex; light blue: FhaA in PknB-(PknB -phytol)-FhaA complex for treating infectious diseases: (1) Series inhibitor, which can inhibit proteins in the same metabolic pathway; (2) parallel inhibitor, which can inhibit proteins unrelated mechanism; and (3) network inhibitor, which is a combination of series inhibitor and parallel inhibitor. ${ }^{[37]}$ Recently, scientists design new multitarget inhibitor for TB.

Recently, scientists design new multitarget inhibitor for TB called SQ109. It has been reported that could inhibit transporter proteins, $\mathrm{MmpL} 3$, manaquinone biosynthesis and ATP synthesis. ${ }^{[38]}$ Nevertheless, it will not effective when only targeting the virulence factor. Otherwise, development of mycobacteria dissemination is also caused by imbalance immune system or other human mechanisms.

From previous studies, oleic acid and linoleic acid could be selective inhibitor of enoyl-acyl carrier protein reductase (FabI) which takes apart in fatty acid synthesis in bacteria. ${ }^{[39]}$ Curcumin has been reported to induce the activation of JNK pathway to activate apoptosis in macrophage. ${ }^{[40]} 8$-gingerol could inhibit mycobacteria survival through it lipophilicity characteristic. ${ }^{[4]}$ Phytol has been also shown that could suppress the mycobacteria infection. ${ }^{[42]}$ Moreover, all of these compounds were shown to attach in the catalytic domain of MMP1, and these indicated disturbed catalytic activity of MMP1 to break collagen which is constituting granuloma. Curcumin, linoleic acid, oleic acid, and phytol have been evaluated which could also suppress the expression of MMP1 gene. ${ }^{[43-45]}$ In Src inhibition, all of the compounds had a various effect toward the Src-PIK3 complex. Curcumin has been reported which could suppress the activation signaling Src/PIK3 pathway for inducing apoptosis. ${ }^{[46]}$

\section{CONCLUSION}

The novel formulation of jamu for TB therapy contained six compounds, curcumin, demethoxycurcumin, 8-gingerol, phytol, oleic acid, and linoleic acid could bind all of the target proteins. According to docking complex, phytol and oleic acid could change the position of Src while a bond 
with PIK3, and in addition, phytol also could change FhaA position while docked with PknB. This novel discovery should be analyzed with advanced simulation to explore the conformation complex. Based on the results, this novel formulation could be TB medication; however, it should be analyzed by in vitro and in vivo research to ensure the effect.

\section{ACKNOWLEDGMENT}

The authors would like to thank Syahputra Wibowo for giving guidance during this research and Science Complex city working group, Department of Biology, University of Brawijaya, for also giving a lot of support and suggestions in this research.

\section{REFERENCES}

1. Raviglione M, Sulis G. Tuberculosis 2015: Burden, challenges and strategy for control and elimination. Infect Dis Rep 2016;8:6570.

2. Summers H. Eradicating Poverty Would Dramatically Reduce TB Cases, Study Finds. Available from: https:// www.theguardian.com/global-development/2018/ mar/24/eradicating-poverty-dramatically-reduce-tbcases-study-finds\#top. [Last accessed on 2018 May 13].

3. Marais BJ, Hesseling AC, Cotton MF. Poverty and tuberculosis: Is it truly a simple inverse linear correlation? Eur Respir J 2009;33:943-4.

4. Suherni NA, Maduratna E. Analisis Pengelompokan kecamatan di kota surabaya berdasarkan faktor penyebab terjadinya penyakit tuberkulosis. J Sains Dan Seni Pomits 2013;2:D13-8.

5. World Health Organization. Brochure on World TB Day, 24 March 2002-Stop TB Fight Poverty. Geneve: World Health Organization; 2003.

6. Cegielski JP, McMurray DN. The relationship between malnutrition and tuberculosis: Evidence from studies in humans and experimental animals. Int $\mathrm{J}$ Tuberc Lung Dis 2004;8:286-98.

7. Nguyen L. Antibiotic resistance mechanisms in $M$. Tuberculosis: An update. Arch Toxicol 2016;90:1585-604.

8. Jain A, Mondal R. Extensively drug-resistant tuberculosis: Current challenges and threats. FEMS Immunol Med Microbiol 2008;53:145-50.

9. Elfahmi HJ, Woerdenbag, Kayser O. Jamu: Indonesian traditional herbal medicine towards rational phytopharmacological use. J Herbal Med 2014;4:51-73.

10. Gharagozloo M, Ghaderi A. Immunomodulatory effect of concentrated lime juice extract on activated human mononuclear cells. J Ethnopharmacol 2001;77:85-90.

11. Kim AJ, Kim YO, Shim JS, Hwang JK. Immunostimulating activity of crude polysaccharide extract isolated from Curcuma xanthorrhiza Roxb. Biosci Biotechnol Biochem 2007;71:1428-38.

12. Kuru P. Tamarindus indica and its health related effects.
Asian Pac J Trop Biomed 2014;4:676-81.

13. Greenlee KJ, Werb Z, Kheradmand F. Matrix metalloproteinases in lung: Multiple, multifarious, and multifaceted. Physiol Rev 2007;87:69-98.

14. Elkington P, Shiomi T, Breen R, Nuttall RK, Ugarte-Gil CA, Walker NF, et al. MMP-1 drives immunopathology in human tuberculosis and transgenic mice. J Clin Invest 2011;121:1827-33.

15. Salgame P. MMPs in tuberculosis: Granuloma creators and tissue destroyers. J Clin Invest 2011;121:1686-8.

16. Roskoski R Jr. Src protein-tyrosine kinase structure and regulation. Biochem Biophys Res Commun 2004;324:1155-64.

17. Chandra P, Rajmani RS, Verma G, Bhavesh NS, Kumar D. Targeting drug-sensitive and-resistant strains of Mycobacterium tuberculosis by inhibition of src family kinases lowers disease burden and pathology pallavi. mSphere 2013;1:e00043-15.

18. Av-Gay Y, Jamil S, Drews SJ. Expression and characterization of the Mycobacterium tuberculosis serine/threonine protein kinase pknB. Infect Immun 1999;67:5676-82.

19. Narayan A, Sachdeva P, Sharma K, Saini AK, Tyagi AK, Singh Y, et al. Serine threonine protein kinases of mycobacterial genus: Phylogeny to function. Physiol Genomics 2007;29:66-75.

20. Almeida Da Silva PE, Palomino JC. Molecular basis and mechanisms of drug resistance in Mycobacterium tuberculosis: Classical and new drugs. J Antimicrob Chemother 2011;66:1417-30.

21. Duhovny D, Nussinov R, Wolfson HJ. Efficient Unbound Docking of Rigid Molecules. In: Gusfield D, Roderic G, editors. Proceedings of the $2^{\text {nd }}$ Workshop on Algorithms in Bioinformatics(WABI), Lecture Notes in Computer Science No. 2452. Rome, Italy: Springer Verlag 2002. p. $185-200,2002$

22. Schneidman-Duhovny D, Inbar $\mathrm{Y}$, Nussinov R, Wolfson HJ. PatchDock and symmDock: Servers for rigid and symmetric docking. Nucleic Acids Res 2005;33:W363-7.

23. Andrusier N, Nussinov R, Wolfson HJ. FireDock: Fast interaction refinement in molecular docking. Proteins 2007;69:139-59.

24. Mashiach E, Schneidman-Duhovny D, Andrusier N, Nussinov R, Wolfson HJ. FireDock: A web server for fast interaction refinement in molecular docking. Nucleic Acids Res 2008;36:W229-32.

25. Laskowski RA, Swindells MB. LigPlot+: Multiple ligand-protein interaction diagrams for drug discovery. J Chem Inf Model 2011;51:2778-86.

26. Daina A, Michielin O, Zoete V. SwissADME: A free web tool to evaluate pharmacokinetics, drug-likeness and medicinal chemistry friendliness of small molecules. Sci Rep 2017;7:42717.

27. Cheng F, Li W, Zhou Y, Shen J, Wu Z, Liu G, et al. AdmetSAR: A comprehensive source and free tool for assessment of chemical ADMET properties. J Chem Inf 
Model 2012;52:3099-105.

28. Bertini I, Calderone V, Cerofolini L, Fragai M, Geraldes CF, Hermann P, et al. The catalytic domain of MMP-1 studied through tagged lanthanides. FEBS Lett 2012;586:557-67.

29. Mak P, He Z, Kurosaki T. Identification of amino acid residues required for a specific interaction between src-tyrosine kinase and proline-rich region of phosphatidylinositol-3' kinase. FEBS Lett 1996;397:183-5.

30. Xu W, Harrison SC, Eck MJ. Three-dimensional structure of the tyrosine kinase c-src. Nature 1997;385:595-602.

31. Wehenkel A, Fernandez P, Bellinzoni M, Catherinot V, Barilone N, Labesse $\mathrm{G}$, et al. The structure of pknB in complex with mitoxantrone, an ATP-competitive inhibitor, suggests a mode of protein kinase regulation in mycobacteria. FEBS Lett 2006;580:3018-22.

32. Karim AF, Chandra P, Chopra A, Siddiqui Z, Bhaskar A, Singh A, et al. Express path analysis identifies a tyrosine kinase src-centric network regulating divergent host responses to Mycobacterium tuberculosis infection. J Biol Chem 2011;286:40307-19.

33. Grundner C, Gay LM, Alber T. Mycobacterium tuberculosis serine/threonine kinases pknB, pknD, pknE, and pknF phosphorylate multiple FHA domains. Protein Sci 2005;14:1918-21.

34. Sandoval-Montemayor NE, García A, ElizondoTreviño E, Garza-González E, Alvarez L, del Rayo Camacho-Corona $\mathrm{M}$, et al. Chemical composition of hexane extract of citrus aurantifolia and antimycobacterium tuberculosis activity of some of its constituents. Molecules 2012;17:11173-84.

35. Siddiqui BS, Bhatti HA, Begum S, Perwaiz S. Evaluation of the antimycobacterium activity of the constituents from Ocimum basilicum against Mycobacterium tuberculosis. J Ethnopharmacol 2012;144:220-2.

36. Ngadino, Setiawan, Koerniasari, Ernawati, Sudjarwo SA. Evaluation of antimycobacterial activity of Curcuma xanthorrhiza ethanolic extract against Mycobacterium tuberculosis H37Rv in vitro. Vet World 2018;11:368-72.

37. Oldfield E, Feng X. Resistance-resistant antibiotics. Trends Pharmacol Sci 2014;35:664-74.

38. Sacksteder KA, Protopopova M, Barry CE $3^{\text {rd }}$, Andries K, Nacy CA. Discovery and development of SQ109: A new antitubercular drug with a novel mechanism of action. Future Microbiol 2012;7:823-37.

39. Zheng CJ, Yoo JS, Lee TG, Cho HY, Kim YH, Kim WG, et al. Fatty acid synthesis is a target for antibacterial activity of unsaturated fatty acids. FEBS Lett 2005;579:5157-62.

40. Li MY, Wang HL, Huang J, Shi G, S, Wan YG, Wang JX, et al. Curcumin inhibits 19-kDa lipoprotein of Mycobacterium tuberculosis induced macrophage apoptosis via regulation of the JNK pathway. Biochem Biophys Res Commun 2014;446:626-32.

41. HiserodtRD, Franzblau SG, Rosen RT. Isolation of 6-, 8-, and 10- Gingerol from ginger rhizome by hplc and preliminary evaluation of inhibition of Mycobacterium avium and Mycobacterium tuberculosis. J Agric Food Chem 1998;46:2504-8.

42. Rajab MS, Cantrell CL, Franzblau SG, Fischer NH. Antimycobacterial activity of (E)-phytol and derivatives: A preliminary structure-activity study. Planta Med 1998;64:2-4.

43. Kim SY, Jung SH, Kim HS. Curcumin is a potent broad spectrum inhibitor of matrix metalloproteinase gene expression in human astroglioma cells. Biochem Biophys Res Commun 2005;337:510-6.

44. Mun SH, Kim HS, Kim JW, Ko NY, Kim DK, Lee BY, et al. Oral administration of curcumin suppresses production of matrix metalloproteinase (MMP)-1 and MMP-3 to ameliorate collagen-induced arthritis: Inhibition of the PKCdelta/JNK/c-jun pathway. J Pharmacol Sci 2009;111:13-21.

45. Bastiaansen-Jenniskens YM, Siawash M, van de Lest CH, Verhaar JA, Kloppenburg M, Zuurmond AM, et al. Monounsaturated and saturated, but not n-6 polyunsaturated fatty acids decrease cartilage destruction under inflammatory conditions: A preliminary study. Cartilage 2013;4:321-8.

46. Shakibaei M, Mobasheri A, Lueders C, Busch F, Shayan P, Goel A, et al. Curcumin enhances the effect of chemotherapy against colorectal cancer cells by inhibition of NF- $\kappa \mathrm{B}$ and src protein kinase signaling pathways. PLoS One 2013;8:e57218.

Source of Support: Nil. Conflict of Interest: None declared. 